\title{
APPROPRIATENESS AND STRUCTURE IN ORGANIZATIONS: SECONDARY SOCIALIZATION THROUGH DYNAMICS OF ADVICE NETWORKS AND WEAK CULTURE
}

\author{
Emmanuel Lazega
}

\begin{abstract}
This paper provides an analytical theory of appropriateness judgments that introduces structural dimensions in the study of social rationality of organization members. This approach helps explore the coevolution of members' relative position in structure and normative choices in their organization. Illustration of this approach is based on the study of controversial judicial decisions and dynamics of advice networks in a courthouse where lay judges have to choose between punitive and nonpunitive awards in cases of unfair competition in business. In this case, coevolution is facilitated by an endogenous process of centralization-decentralizationrecentralization of advice networks over time, and by use of a procedural "weak legal culture" that helps align and homogenize conflicting normative choices among organization members. It is suggested that this
\end{abstract}

Contemporary Perspectives on Organizational Social Networks

Research in the Sociology of Organizations, Volume 40, 381-402

Copyright (C) 2014 by Emerald Group Publishing Limited

All rights of reproduction in any form reserved

ISSN: 0733-558X/doi:10.1108/S0733-558X(2014)0000040019 
approach to social rationality helps revisit our understanding of social processes, in this case collective learning and secondary socialization in organizations and flexible labor markets.

Keywords: Centralization-decentralization-recentralization; collective learning; epistemic alignments; social control; social mechanisms; organizational society

Sociological work on the articulation of individual action and collective action in organizations can be based on the idea that actors contextualize their actions and exchanges. This paper argues that this notion of contextualization is under-explored in the sociological theories of rational and strategic behavior in the workplace, and that it is possible to refine it by taking into account the ability of actors to evaluate the social and organizational appropriateness of their actions. This capacity covers the definition of the social premises of these actions, premises that may be considered "knowledge claims," both inextricably epistemic and normative. The outcome of this contextualization is the choice of a rule for individual action that contributes to collective action.

Actors who contextualize their conduct use social bearings. They evaluate the appropriateness of a course of action with respect to bearings such as a set of rules, a reference group, and authorities, that is, members with social status who represent this reference group, validate the interpretation of the rule and provide social (dis-) approval for the behavior. In the sociological literature, the appropriateness judgment synthesizing these elements can be compared with the ideal-typical process of "defining the situation" as it has been theorized by the "structural" branch of symbolic interactionism (Gonos, 1977; Hughes, 1945; Lazega, 1992, 2011a; Maines, 1977; McCall \& Simmons, 1966; McHugh, 1968; Stryker, 1980) and microsociologists (e.g., Esser, 1996; Lindenberg, 2006). Rules, reference groups, and status: the praxeology contained in this theory emphasizes the control that actors exercise over their own actions, that is, a form of social rationality that is inseparable from self-discipline, even self-censorship. Indeed contextualization through appropriateness judgments is an issue, increasingly, when organizations expect members to be self-disciplined, to exercise social control on their own actions unobtrusively.

This paper first proposes an analytical definition of the appropriateness judgment that introduces structural dimensions in the social rationality of organizational members. Thus defined, appropriateness judgments reflect 
a framing that is epistemic, strategic, and praxeological. The theory of this judgment specifies these dimensions of framing in Goffman's (1974) sense, but in a manner that makes it conceptually articulable with the fundamental dimensions of the structure of the collective. Thus it offers a sociological approach to framing conflicts or conflicts of definitions of the situation which are often, in much of contemporary organizational studies, more directly psychologically relevant and intra-individual, that is, disconnected from strong dimensions of social structure. It suggests that it is the combination of these dimensions of framing that gives, through the collective dimension of epistemic approval, a moral force to its normative choices.

Second, the structural dimensions of this contextualization is highlighted using social network analysis, particularly analysis of intra-organizational advice networks. The appropriateness judgment thus becomes partly observable, and this measurement in turn reinforces the modeling of the process of co-orientation, collective learning, and secondary socialization in organizations. These are fundamental processes of collective action, especially where the capacity for adaptation through learning and secondary socialization to new organizational contexts is an important competitive advantage for individuals and organizations in flexible labor markets. Through the specification of the dimensions of the appropriateness judgment, examination of these processes constitutes a contribution to the sociology of organizations and knowledge because the relationship between knowledge, epistemic validation, and social authority comes to light particularly well in the analysis of advice networks, especially in the analysis of their dynamics. Such dynamics are part of coevolution of appropriateness judgments and position in the relational structure in organizations, a coevolution that is shown to be akin to epistemic alignment and synchronization with normative choices made by specific epistemic leaders.

This articulation of a theory of appropriateness judgments with organizational network analysis is illustrated using an empirical example and its implications for the understanding of secondary socialization in the organizations. The empirical study looks at controversial judicial decisions and dynamics of advice networks in a courthouse where lay judges have to choose between punitive and nonpunitive awards in cases of unfair competition in business. In this case, coevolution of structure and appropriateness is facilitated by an endogenous process of centralizationdecentralization-recentralization of advice networks over time, and by use of a procedural weak legal culture - a variant of Breiger's (2010) "weak culture" - that helps align and homogenize conflicting normative choices among the organization's heterogeneous members. 


\section{APPROPRIATENESS JUDGMENTS AND STRUCTURE}

This theory of the definition of the situation can analytically decompose the appropriateness judgment in at least three operations (Lazega, 1990, 1992). Responses brought by the actors to the "generic" questions asked at each step constitute the social premises of contextualized action and are deemed appropriate. They allow for "co-orientation," defined as a stabilization of epistemic interdependencies and sharing appropriateness judgments, a key moment in the coordination of collective action. This specification of the dimensions of the appropriateness judgment echoes the ideas of the structuralist branch of symbolic interactionism - a branch that can make use of the Mertonian concept of opportunity structure and see in established structures the outcome of historical processes that have an indirect effect on action (Fine \& Kleinman, 1983).

First, for a given or proposed action (e.g., appropriation, production, selection of exchange partner, exchange), which is the epistemic reference group (or "epistemic community" in the sense of the group sharing the same appropriateness judgment) that has priority for the actor? "Appropriate" knowledge is close to "satisfactory" knowledge with respect to the pragmatic requirements of action, but also with respect to social control. Which is therefore this instance of social control from which actors await epistemic approval? If action is the result of socialization and individual dispositions that it creates within the collective, it is also the result of influences and social sanctions. One may thus ask from which collective, of which they believe to be members, the actors expect in priority the validation or approval for the choice of a rule and subsequent actions? For symbolic interactionism, the answer is in the identifications of the actors, in the hierarchy of allegiances that allow them to be recognized as the sources of their own actions (Stryker, 1980). Actors negotiate their identity in a manner that ranks several possible reference groups, and thus several instances of social control. This ranking, or hierarchy of allegiances, constitutes the first social premise of action.

A second social premise lies in normative choices in a polynormative context, a choice that has often been seen as adding a social dimension to human rationality (Reynaud, 1989). This choice of a rule among competing rules allows for legitimization of action on behalf of the priority reference group. To which rule, cultural norm or precarious value (Selznick, 1957) does one refer in a situation of normative ambiguity or polynormativity, that is, when several rules could be culturally recognized as legitimate within an organization? From the point of view of the "previously" recognized 
instance of social control, actors are endowed with reflexivity and able to problematize their own actions, for example, to anticipate or prevent their induced consequences and their possible delegitimization. It is this choice of a rule that establishes the legitimacy of an act and the manner in which actors involve social control in the orientation of their actions or exchanges. Legitimacy can be produced through deliberation, critical debate, and justification; it nevertheless remains highly dependent on authority relationships and a prior distribution of access to authority arguments (hierarchical or expert) in organizations.

Rooting appropriateness judgments in rules via socialization and culture does not reduce the complexity and importance of culture (White, 2008). Combined with the notion of "cultural hole" (Breiger, 2010; Pachucki \& Breiger, 2010; Schultz \& Breiger, 2010), appropriateness judgments create room for consensual rules and regulatory activity as stemming from "weak culture." Indeed Breiger (2010) and Schultz and Breiger (2010) propose that the tie that binds an actor to a cultural taste, for example, "might be strong (purposive, intensive in time or commitment, fostered by a tightly integrated community bounded by social symbols and representations) or weak (banal, noninstrumental, nondemanding, nonexclusive)." They find that weak culture can be "strong" in several different respects, for example, "by bridging across otherwise disconnected social groups, or by bonding actors to a wider collectivity than is possible on the basis of strong-culture commitments." They report research findings indicating that weak culture, that requires no strong commitment from actors, tends to span preferences and does not need strong approval. In spite of being weak, "weak culture has a strong and significant impact on shaping attitudes about (...) values." Their reasoning is that, with its capacity to help create heterophilous ties, weak culture regenerates structure by bridging across diverse social milieux. In our view this process can help actors in recreating a hierarchy of allegiances and bringing together competing reference groups.

A third social premise lies in the choice of a representative for the priority reference group, among its members. Who states and interprets the rule in a context of normative ambiguity, of precarious values (Selznick, 1957)? For Selznick, a value is "precarious" not in that it is "revisable," but rather in that it is threatened by the weakness of its spokesmen. The enunciation of this rule is always personalized, in any given context, because leaders need the support of members of the collective to the main objectives that they define. In the relationship between a leader and followers, there always remains a certain ambiguity. Since s/he seeks the support of the members of the organization to the objectives that s/he defines, s/he finds it easier 
and more comfortable to confuse it with support to her/his person (Bourricaud, 1964). This personalization creates an articulation between norms and social structure. This step corresponds with a personalization of the authority to which one is accountable for one's actions, from which one seeks social approval. It concerns at the same time the way in which actors recognize forms of social status and localize social control in the structure of their collective. The influence of norms on action is indeed mediated by this articulation between norm and social structure. In an organized social setting, where authority arguments are carefully allocated, the choice of a representative also indicates, ipso facto, the choice of the authority argument with the last word, before which actors accept to yield as a last resort. It follows that social rationality is inseparable from authority relationships, particularly in organized collective action. The contextualization of action cannot avoid encountering the power and authority structure as it is established in the organized group.

This analytical definition of appropriateness judgments introduces vertical and horizontal differentiations, i.e., structural "forms" in the social rationality of actors, such as social niches and social status (Lazega, 2003). We propose to further specify the theory of this rationality by using the fact that these structural dimensions can be measured in organizations. The observation of social networks, in particular intra-organizational advice networks, helps here with this empirical step. Sociologists of organizations observe these networks very closely in the study of learning, adaptation and co-orientation processes. Co-orientation, epistemic alignments, and the relationship between knowledge and authority become more easily observable in such networks because seeking advice from someone means attributing a form of social status (Blau, 1964; Krackhardt, 1990) and epistemic authority (Lazega, 1992) to this advisor. ${ }^{1}$ We use the fact that advice relationships in organizations open a small window for the observation of appropriateness judgments in the heart of social rationality.

\section{DYNAMICS OF ALIGNMENT AND SYNCHRONIZATION: COEVOLUTION OF APPROPRIATENESS JUDGMENT AND POSITION IN ADVICE NETWORKS}

Appropriateness judgments depend heavily on how actors manage their epistemic interdependencies. ${ }^{2}$ In particular, the reconstitution and analyses 
of advice networks is a first step in this direction. Advice networks are not the only networks through which this tension between authority, norms, and identity can be observed. The use of advice networks to approach appropriateness judgments is based on their use as an indicator of epistemic interdependencies. Advice does more than transmit information. What is being transmitted in a pragmatic manner in an advice relationship is also a framework for the evaluation of this information, the elements necessary for the evaluation of its appropriateness.

It is not uncommon, for example, that one comes to reformulate with the adviser the question itself which was being asked initially. The advice seeker is then in a situation of "meta-ignorance" (Smithson, 1985). Under such uncertainties about the very nature of the demand ("What would you do if you were in my shoes?"), the latter often includes demand for social approval or legitimization. One can therefore assume that actors use status criteria when selecting an adviser (Blau, 1955, 1964), a fact so often observed by network analysts studying advice networks (Barley, 1990; Borgatti \& Cross, 2003; Brass, 1984; Cross, Borgatti, \& Parker, 2001; Ibarra \& Andrews, 1993; Kilduff \& Tsai, 2003; Krackhardt, 1990; McDonald \& Westphal, 2003; Mizruchi \& Stearns, 2001; Rulke \& Galaskiewicz, 2000; Tsai, 2002) or sometimes simply discussion networks (Burt, 2004). Recognition of status gratifies the advisers by providing them with an incentive to share their knowledge and their experience. In formally organized contexts, following this status rule, members avoid seeking advice from the colleagues "below" them in the formal hierarchy or in the pecking order (Krackhardt, 1990).

These asymmetries are not necessarily rigid. Empirical research finds many "infractions" to this rule. Actors use several kinds of similarities among themselves to mitigate the conflicting effects of these status games. The use of homophily in the choice of exchange partners allows members to find "shortcuts" in the access to intelligence necessary to the resolution of problems (Lazega \& Van Duijn, 1997; McPherson, Smith-Lovin, \& Cook, 2001). Thus, to the extent that advice networks are structured by these status games and by their mitigation, they tend to become both hierarchical and cohesive, the hierarchical dimension being often stronger than the cohesive dimension. They are also strongly embedded in other types of social networks that help with mitigating the status rule (Lazega \& Pattison, 1999). This embeddedeness already signals the presence of reference groups or epistemic communities.

The temporal and dynamic dimensions of appropriateness judgments also appear in structural analysis. Members can "unlearn." They can realize that their information is obsolete, update their knowledge claims, change, 
disqualify, or requalify epistemic authorities, modify their epistemic alignments. This is shown by the endogenous evolution of advice networks, which is characterized by three interrelated moments (Lazega, Lemercier, \& Mounier, 2006; Lazega, Sapulete, \& Mounier, 2011). First, the centrality of members with high epistemic status varies over time. At first, it tends to be reinforced. Central members become increasingly central, in a Mertonian process close to "preferential attachment": those who are sought out become increasingly sought out because they have built a reputation. Members who seek out are increasingly under the impression that selecting these sources of advice is safe and legitimizing for their knowledge claims, and that this choice signals an increase in relative status. Concentration of epistemic authority increases with the centralization of advice networks: learning becomes increasingly dependent on a smaller and smaller number of sources of authorized knowledge.

Second, however, in real life organizations, this centralization creates an overload for members with high epistemic status. They therefore tend to manage this overload by sharing a part of their epistemic status - through recommendations, that is, by redirecting advice seekers to other sources. When advice provided by the very few super-central advisors becomes inaccessible or very rare, members turn to these other advisers, creating new epistemic stars. Sharing epistemic status, a form of delegation, increases the number of advisers and decreases the centralization of the network.

Third, the increase in the number of central members with high epistemic status in the organization creates a problem of epistemic conflicts, consensus, and coordination among epistemic authorities. If their co-orientation is easy, equilibrium is established. If not, conflicts between epistemic authorities trigger a reverse process of recentralization. When the danger for collective action is that there are "too many chefs" here too, that is, epistemic leaders, some withdraw or retire, others are sidelined or ostracized by one form or another of disqualification. As their numbers decrease, it becomes easier at the top to recreate consensus around a common definition of the situation, to provide coherent social benchmarks for homogeneous appropriateness judgments and the reconstitution of an epistemic community.

These dynamics of centralization and decentralization in advice networks may not be purely endogenous (in the sense that overload through centralization leads to the super-central advisors creating new epistemic stars by redirecting advice requests to surrogates): indeed the patterning of advice relations can be influenced by the content of what one is seeking advice about; and by external events that may make one potential advisor a better source of advice than another. However the existence of this 
endogenous dimension of the process provides at least one mechanism explaining (see below) how a category of super-central elites is able to stabilize its position and surf at the top of the structure regardless of strong competition for epistemic authority and status.

Coevolution of appropriateness judgments and position in the structure (relative position in status terms) sees alignments as synchronization with epistemic authorities. The cyclical dynamics of advice network centralization-decentralization-recentralization is generated by a search for a balance between overload and conflict. When the epistemic pecking order is not very stable, dynamics of advice networks provide empirical indicators of challenges to authoritative knowledge, to appropriateness judgments, and to authorities that validate it. It thus gives additional indications about the inner workings of appropriateness judgments in the specification of the premises of decisions or actions. In particular, it shows that it is through the co-evolution of relational structures and conventions or norms that sociologists of organizations can measure processes of social learning (Lazega \& Favereau, 2002; Lazega, Mounier, Snijders, \& Tubaro, 2012). Actors and their groups do not learn mechanically. This capacity to learn collectively depends particularly on their reframing capacities in changing networks, that is, in their "switching" capacities across social boundaries (Breiger, 2010; White, 2008).

As the network becomes increasingly centralized, more and more members are exposed to the norm of new epistemic leaders, who become more legitimate in a polynormative context. An empirical example may help illustrate this approach of coevolution of appropriateness judgments and position as alignment and synchronization through longitudinal analysis of advice networks and knowledge claims in an institution.

\section{ILLUSTRATION: ALIGNMENT OF JUDICIAL DECISIONS AND SYNCHRONIZATION IN A COURTHOUSE}

Illustration for such processes can be found in a case in point of coevolution of advice networks and normative choices through emergence of weak (here: procedural) culture in an organizational context. The French commercial court is a judicial, local, first-level "consular" ${ }^{3}$ jurisdiction dealing with commercial litigation and bankruptcies in the French economy. Its judges are voluntary, unpaid, lay business people who pool their 
experience and knowledge of business practices and customs to find solutions to these conflicts. They are elected/coopted for 14 years maximum by an electoral body composed of sitting judges at the same court and by representatives of trade associations at the local Chamber of Commerce of the jurisdiction. Most consular judges stay for the whole tenure of 14 years. Turnover is not frequent, which allows social communities to arise and be sustained in the organization. Twenty-nine percent of the 160 (on average) consular judges at the Commercial Court of Paris (2000-2005) were bankers since the only industry that can afford today to send massive numbers of high level managers to act as judges in such an institution is the financial industry. For a detailed presentation of this qualitative and quantitative study of this institution and its results, see Lazega et al. (2006, 2011, 2012; Lazega \& Mounier, 2003, 2009, 2012).

\section{In Mode, In Sync}

Judges are often considered emblematic of rational actors. In a sensitive domain such as justice and judicial institutions, normative and epistemic conflicts are more accepted and explicit than in many other domains of social life, which allows for approaching more easily than in other contexts the ways in which actors' judgment criteria evolve as well as the coevolution of their networks and of their normative choices. During research on lay judges at the Commercial Court of Paris, we observed the articulation of the components of this appropriateness judgment in a specific situation: the decision to be or not to be "punitive" for the resolution of a problem of unfair competition between two companies, that is, to evaluate the damage suffered by the plaintiff and to award "moral" damages. This is typical of a case where the law does not offer an immediate response and where it is difficult to make a decision. In this type of situation, judges have a great amount of discretion. The premises that they find appropriate for their decision can play an important role.

At this Court as elsewhere, judges raise the fundamental question of the meaning of reparation, all the more so as economic actors are companies. The judge wonders if the damages are meant mainly to help recondition the company in all its components (physical and moral, for example) or if they are meant, also, to be sanctions that have a moral and punitive dimension. ${ }^{4}$ We observed, within the Court, a controversy on this subject. This controversy allowed the judges to know their respective positions in this field. Indeed, all the consular magistrates do not reason in the same way 
about the evaluation of "moral" damage suffered by a corporate actor, an indicator of their punitivity. In deciding to adopt a rule in that field, the judge follows one of two logics of action, i.e., may reason as a "righter of wrongs" or as a "mediator."

If he ${ }^{6}$ entered a "righter of wrongs" mode, the commercial judge had a tendency to support the punitive rule: he adopted the rhetoric of the entrepreneur, called on his experience of the harshness of business life and, based on this experience, decided to compensate the moral damage despite (or sometimes even because of) the difficulty of providing evidence and evaluating this type of damage. As collective damage comes attached to an individual damage, this behavior leads to the destruction of market circuits considered as "natural" (in the neoliberal point of view which is that of most of the judges of this Court). The question is then asked in terms of the accountability of business people. The "righters of wrongs" concluded that if the notion of fault, the measure of its gravity and punishment are not present, there is a high risk of unaccountability and chaos in business practices. Without punishment, business would become too anomic and favor cheaters too much.

If he entered a "mediator" mode, a commercial judge had a tendency not to support the punitive rule and to consider the "righter of wrongs" a dangerous, idealistic visionary to whom it is necessary to oppose the strict application of legal procedure. Positive law admits a moral damage for corporations and its repair, provided that the existence of damage is proven (Article 1382 of the French Civil Code). However, to prove moral damage for a corporation is very difficult. The nonpunitive approach is not only based on this strong procedural argument. It is also popular with business because it fits well with the consular ideology of reestablishing a link between the infractor and the victim, both entrepreneurs who need to be able to continue to do business together after court proceedings. Thus, the Commercial Court is often instrumentalized by parties who use it to renegotiate their contracts. Entrepreneurs must then search as much as possible for mediations and amicable agreements that do not accommodate a punitive rule.

Because of the uncertainties that surround the decision, the judge has a great amount of discretion, but he can also partially control these uncertainties through exchanges of ideas and advice from his colleagues. Epistemic interdependencies between judges working together on a case can be very strong during formal deliberations. But they remain strong outside of formal deliberations, if only to recall earlier deliberations or to prepare for future ones. As a result, judges needed co-workers, advisors, and 
interactions with other judges of the Court. The choice of the rule then happened in social exchanges taking place in identifiable relational structures and in reference to specified epistemic authorities and communities.

When the law does not provide a clear solution, this Commercial Court becomes an organization divided by a struggle for epistemic influence. At stake is the construction of a collective norm, and more generally of a common reference framework that is indispensable for the qualification and stable interpretation of facts in judicial reasoning. In this competition between epistemic communities, leaders, and frames, the transition from the domination by one mode to the domination by another requires the replacement of one epistemic elite by another - that is to say the arrival of an epistemic elite carrying or representing a new kind of appropriateness judgment: a new definition of the situation, a new criteriology, a new rhetoric, and new "precarious" values in Selznick's sense. It is therefore important to identify the actors and coalitions that are in a position to gradually promote their pragmatic sensitivities, collective representations, and criteria of justice (Lazega, 2011b).

Based on the theory of appropriateness judgments, the choice by the judge of the legitimate rule among several possible rules takes place, analytically speaking, along with two other steps: the identification of the reference group with which the actor is in sync, and the identification of epistemic leaders who state or interpret the rule on behalf of this reference group.

\section{Money Talks}

The analysis of the advice network combined with that of the attributes of the judges within the Court establishes statistically (Lazega \& Mounier, 2009) that to enter a "righter of wrongs" mode was to be in sync with an epistemic reference group composed of young judges, professionally active, without legal education. The main voices in this epistemic community were the judges coming from the Building and Public Works sector. They had, more than other judges, the tendency to reason in this manner and to use the rhetoric that diffuses this reasoning. They had a reputation for hitting hard and speaking loud (as if on a construction site, other judges joke). They came from an industry that is structured as a cascade of subcontracting deals that generate an unusual amount of conflicts and litigation with sub-contractors forced to reduce their costs and accept ever shorter deadlines, that is, impossible conditions just to win the contracts. They recruit clandestine labor and take big risks with their health, even their lives. 
Legally, they very quickly find themselves in situations that must be dealt with by criminal law, rather than civil law, thus calling for a punitive rule. From the perspective of the legal culture of these punitive judges, purely procedural arguments (such as "bring me proof of moral damage; if not, no money") interfered with their righter of wrongs "mission." The absence of proof of the pain endured by the suffering entrepreneur (and pressured company) was considered an inappropriate argument. For these judges, it was not acceptable to ignore this reality just because it is difficult to prove.

On the other hand, as shown by the same analysis, to enter a "mediator" mode was to get in sync with an epistemic reference group composed mainly of senior, professionally retired, legally educated judges. Lay judges coming from the banking, insurance and, more generally financial sectors, tended to reason in this manner more than the other judges, and to use a rhetoric that makes it possible to share that reasoning. The legal culture of these judges encouraged them to stress the procedural question of proof: it is up to the plaintiffs to establish their loss. Insofar as proof is not brought up, even if it is difficult to bring up, they did not compensate for moral damage. For the righter of wrongs coming from the BPW industry, the mediators-bankers with a law degree knew more about company boards than about real markets (other than financial markets) and rely more dogmatically on the letter of the law because they had a strong lobbying influence on the political process (of formulating those very same laws, upstream of the judiciary). Their nonpunitive position was considered at best proof of inexperience ("Those who never experienced the dirty tricks of business cannot understand; when you lived through these tough experiences, you are no longer the same") or at worst proof of incompetence, partiality, or inhumanity. They sometimes accused the mediators-bankers with a law degree of discarding moral damage because damages sought out by plaintiffs can easily reach very high amounts; banks having the deepest pockets in the business world become more easily and systematically the targets for this type of compensation claim.

One side criticized the systematic use of procedural arguments, arguing that they should not count, and that what should count is a knowledge of real-life markets (i.e., other than financial markets), and the defense of business ethics strengthening markets' reliance on self-discipline and selfregulation. For the other side, there is no room for compassion in business because it is not decent (and therefore appropriate) to express feelings of injustice related to moral damage in a context where "a businessman's morality is in his drawer box" (which means that he is not expected to have any morality whatsoever). The position of each epistemic community at the 
Court was easily radicalized to the point of calling into question the impartiality of colleagues on the other side. The strong verbal violence of some of these attacks came from those who both formatted and were formatted by one type of appropriateness judgment supported by power relationships, social affiliations, and a rigid hierarchy of allegiances.

In the controversy, some voices rose above the others. The study of the evolution of centrality in advice networks, as it was observed between the first and the third waves of fieldwork, made it possible to identify these epistemic leaders, whether nonpunitive or punitive. Statistical analysis shows that most judges were punitive righters of wrongs and sought advice from similar colleagues. But a nonpunitive group of mediators emerged over time, led by a small elite of nonpunitive super-central judges who became increasingly central and sought out for advice. The centrality of these judges was far higher than that of the average president of chamber. Over time, an increasing proportion of judges referred to this small group of super-central epistemic leaders with both hierarchical (president of chamber) and expert (legal) authority arguments who were essentially bankers with a law degree. An interesting process of alignment, that is, of synchronization, of righters of wrongs on mediators unfolded. In the courthouse, over 10 years, we observed that it became increasingly unfashionable and socially inappropriate, even frowned upon as dangerous for the reputation of consular justice, to make punitive decisions and give away punitive financial awards. Punitive judges were resocialized as nonpunitive. They were not asked to give up on their beliefs in fighting "chaos" in the economy, just to adopt, as part of a new organizational culture, more procedural rules that increased social disapproval for punitivity and decreased their capacity to enforce their punitivity. ${ }^{7}$

In this illustration, an identity choice is combined with a rule considered legitimate (to be or not to be punitive) and with a struggle for control. This specifies and measures in a systematic manner some of the ingredients of the appropriateness judgment. It combines a relational opportunity structure with a discursive opportunity structure. By identifying the context in which a specific discourse is considered acceptable, it revisits the relationships between authority, social exchange, and knowledge.

\section{REVISITING SECONDARY SOCIALIZATION IN ORGANIZATIONS}

This paper proposed a definition of appropriateness judgments as reflexive contextualization and interpretation of actions that endogenize various 
dimensions of social structure. At least three operations, analytically speaking, qualify this definition: ranking of identity criteria and reference groups, choice of convention or rule considered legitimate in this group, and identification of representatives of the group considered legitimate spokespeople for the choices of rules. Observing the evolution of advice networks in this organization traces the evolution of appropriateness judgments in this institution and its framing conflicts over unfair competition in markets. Measurements show that the epistemic authority of nonpunitive leaders increases, to the detriment of punitive attitudes in a collective learning process. The dynamics of these advice networks expose the conflicts of authority and of epistemic allegiances when one combines structural analyses of networks with more qualitative and interpretative analyses of the arguments of members and of the rhetoric of their epistemic leaders or representatives. While becoming increasingly central over time, super-central epistemic leaders succeed in creating epistemic changes or realignments.

Super-central epistemic leaders' procedural justice was a "weaker" form of legal culture that was easier to share across social differences and boundaries than the more substantive law and arguments of the writers of wrongs. The analysis of the coevolution of the network and of the associated rhetoric shows that our observation captured a moment of transition from one epistemic control regime to another. A process of social learning in the advice network lead to the reinforcement of the nonpunitive rule promoted by bankers with a law degree who had taken epistemic control of the Court. This process was based on epistemic convergence, a process that is more or less forced by alignment on the positions of epistemic leaders, whose particular and stronger influence was recognized as legitimate, and who mustered sufficient authority to give moral force to the appropriateness judgment. This convergence was facilitated by the fact that these epistemic leaders arguments were mainly procedural: if one accepts that legal procedure is an instance of "weak culture" in Breiger's (2010) and Schultz and Breiger's (2010) sense, then we find in this increased influence of "procedural non punitivity" an additional case in point of the phenomenon of the "strength of weak culture" that they have identified. This view is consistent with Mohr and White's (2008) assertion that "what makes an institution work is that it interpenetrates the social with the cultural." It is at the same time, in the case of this institution, a process of invisible institutional capture (Lazega, 2011b; Lazega \& Mounier, 2012).

To conceive and analyze appropriateness judgments in these terms is interesting for contemporary sociology of organizations in two respects. First, this approach to social rationality and knowledge claims that serve 
as premises for decision and action in organizations can be tested with social network analysis. This link enhances classical discourse analysis, gives concrete meaning to the notion of contextualization, and makes endogenization of the structure a measurable phenomenon. This methodology in turn places conflicts of allegiances, conflicts of authorities, and rules at the heart of epistemic framing and, consequently, of individual action and social processes characterizing collective action. Second, this approach proposes a systematic examination of such social processes - in particular co-orientation and collective learning in organizations that are increasingly concerned with secondary socialization.

Managing secondary socialization is both central and problematic in contemporary organizations because of increased flexibility of labor markets that puts members in increasingly open competition and imposes upon them increasingly frequent mobilities and bifurcating trajectories. In effect, co-orientation is a precious part of social capital for collective action. We know for example that leaders spend time and energy to make sure that their teams are "tuned in." Thus they hope that the more members of the organization will have access to the same information, will be aware of the same developments, will share the same identity criteria and the same norms and values, the more they will act in identical ways without even needing to discuss coordination. The existence of a common socialization process, constantly nurtured and updated, is often perceived in organizations as an essential source of energy and coherence of the whole.

This epistemic coordination has thus become an object of research and of efforts of rationalization. Contemporary organizations, in particular in the knowledge economy, are oriented toward collective functioning where brutal use of power is often hidden and where self-discipline, if not selfcensorship, the ability to act in sync and to align oneself on epistemic authorities, are increasingly positively valued. These abilities are no longer considered to be exclusively leaders' abilities. When the evolution and organizational changes are fast, when tasks are not (entirely) routine, exclusively bureaucratic management of the collective action is ineffective. Decentralization, collegiality or individual improvisation are essential, as is coordination by co-orientation. The construction and sharing of common frames of reference, that is, of the same appropriateness judgments, becomes more systematic, complex, and sophisticated. Individuals are increasingly encouraged to exercise independent judgment, but also increasingly engage in a struggle for the control of the premises of this judgment and for the control of the shared criteria used to solve problems of co-orientation and coordination. 
To control this self-discipline in an indirect manner, managers thus try to rely on the idea of engineering an organizational culture that is taken for granted and that helps the collective to act in a coordinated manner without public deliberation, consultation, and meetings. They thus presuppose the existence of a single epistemic community within the organization. Contemporary organizations seek to "equip" this single epistemic community with the "right" appropriateness judgments that can be learned quickly, that is to say, to create a context that facilitates certain consultations rather than others, that promotes predefined attitudes and conceptions of self and of "us." Adoption of this "equipment" is therefore a true secondary socialization of individuals. There is no collective learning without such a secondary socialization based on sharing appropriateness judgments. There is no sharing of such judgments without using the same reflexivity and contextualization based on endogenization of the same structural forms, including reference groups and status, often as a result of (forced) epistemic alignments. Much of the success of collective learning will thus depend upon actors who can manage to represent with some legitimacy such a form of status. Once a dominant organizational culture is defined, however, one notes a tendency to try to forget the conflicts (which often generated this culture) by concentrating social control and authority arguments (hierarchical and expert) in the hands and discourse of the same epistemic authorities, thus excluding dissenting voices. While tensions created by indirect control of action, through presetting of appropriateness judgments and of premises of decisions, are increasingly important and frequent, organizations require secondary socializations that may be frequent, costly and socially problematic, but also quickly "normalized" and naturalized.

\section{CONCLUSION}

In conclusion, recognizing actor's reflexive ability to judge the social appropriateness of his/her actions enriches the definition of social rationality and improves the comprehension of processes such as collective learning and secondary socialization that are central in contemporary organizations and labor markets. This capacity of judgment and contextualization applies to the definition of social premises of decisions or actions. These premises can be considered as knowledge claims. Combining symbolic interactionism and dynamic analysis of networks of epistemic interdependencies, our approach deconstructs appropriate judgments through some of their 
components that are more accessible to observation, measurement, and modeling. It uncovers conflicts of appropriateness judgments and their consequences where modern organizations often like to think of themselves as monolithic epistemic fortresses whose members unconsciously use their pre-elaborated premises. The exploration of the coevolution of appropriateness judgments and relational structures in the analysis of advice networks, as well as the use of the concept of the "strength of weak culture," have the advantage of making these epistemic and ideological conflicts more readable. It locates epistemic alignments that are consequences of such conflicts and that are central in collective learning processes, co-orientation, and secondary socialization in organizations; but also for understanding the complexity of social rationality and the latter's importance for the life of institutions such as the court that was used here as an illustration for this approach. Network analysis - in particular when it is combined with a symbolic interactionist theory of action and when it is simultaneously able to model processes at the sub-structural and at the structural level - shows the extent to which managerialization of such social processes relies on the existence and maintenance of stable social forms, for example epistemic communities and epistemic status. It also shows how deep this managerialization reaches in members' minds and sense of self in order to engineer, steer and control these social mechanisms in the organizational society. Finally, it can help measure invisible costs of secondary socialization to individuals, particularly to those switching jobs frequently on the labor markets.

\section{NOTES}

1. This sociological tradition considers that seeking advice from someone confers a form of social status on the advice giver even when advice is sought out and not followed. Indeed advice seeking can be used to placate others or signal that one is more democratic and open to suggestions than one actually is (at least some bosses seek advice from subordinates, depending on what they are seeking advice about). This does not mean that inference of status from the observation of patterns of advice seeking is the only way to learn about co-orientation and epistemic alignments. Using friendship ties, which are less constrained by organizational roles, could shed a different - perhaps complementary - light on epistemic alignments.

2. I find this term to be more adapted to a structural perspective than that of "cognitive" interdependencies because the latter is often rooted in psychologically relevant, exclusively intra-individual mechanisms where social and organizational 
structures are under-theorized - that is, for which concepts such as identity, reference groups, status, and authority arguments are marginal in the theory of human information elaboration. For an exception to this statement, see psychological theories of framing related to categorization and interdependence of actors in terms of affecting each other's categorizations: for example, Lindenberg (1997) provides a link between individuals' purposeful action, cognition, and social structure through consistency of framing with relational choices (structural interdependencies) and task related (functional) interdependencies. But even there, cognitive steering of behavior by goals through attention and attribution of salience is heavily rooted in individual psychology and less attention is paid to external, organizational cues about what is and is not appropriate behavior than in a symbolic interactionist perspective.

3. An explanation of the term consular is in order. The consulat was a mode of urban government practiced in the Middle Ages in the southern part of the Kingdom of France by cities with a right to self-administration and self-defense. "Consulatus" is formed from "consul," meaning "council." The word referred to a community's ability to deliberate together in an assembly likewise called the consulat. Urban communities governed by a consulat could call themselves cities. All had markets and many had fairs. In a "régime consulaire" the community governed itself by way of consuls, who varied in number and by qualifications. Merchants organized into socially distinct guilds occupied an important place in the régime consulaire. On the basis of the lex mercatoria, they managed to negotiate with the emerging French State a kind of joint regulation of their business activities within the consulat framework: their local self-regulation was to be founded on the State's sanctioning power. The State, meanwhile, whose own administration was as yet embryonic, may paradoxically have seen this cooptation by local merchants as a means of further extending its central control over the country. A major component of the "consular regime" is the tribunal de commerce or commercial court, whose content evolved over time.

4. We find here Durkheim's concepts of "repressive sanction" as opposed to "restitutive sanction" that are used in the preface to the second edition (end of Chapter I) of the Social Division of Work, as well as the notion of repressive versus restitutive law (Chapter VII).

5. Judges' reasoning was reconstituted based on vignettes (Lazega \& Mounier, 2009). Given the specificity of this court, the difference between the mediator and the "righter of wrongs" is not entirely captured by the difference between a judge who makes a decision and a judge who leaves it up to the parties to reach a form of consensus that $\mathrm{s} /$ he will then ratify. Each mode represents a different "project" or perspective for the judicial institution.

6 . I choose to use the masculine mode because $85 \%$ of the consular judges at this Court were male.

7. At the time of the study, half of the lay judges were retired. For those still active as employees of companies, the judgments they delivered, when handling large cases that were followed by the media (such as cases of bankruptcy with layoffs of thousands of workers; or cases in which plaintiffs received tens of millions of euros in damages), may impact their reputation in their "regular" jobs. However if the decision to adopt a "mediator" versus "righter or wrongs" approach had to 
do with the impressions of self they were trying to create in the eyes of constituencies other than the lay judicial institution in which they were rendering decisions, for example, their reputation in their "regular" jobs, then most judges would have stuck with punitive decisions and the culture of the court would not have changed. We observed exactly the opposite.

\section{ACKNOWLEDGMENTS}

I thank Ronald Breiger, Sheldon Stryker, and the anonymous reviewers for stimulating discussions and comments.

\section{REFERENCES}

Barley, S. R. (1990). The alignment of technology and structure through roles and networks. Administrative Science Quarterly, 35, 61-103.

Blau, P. M. (1955). The dynamics of bureaucracy. Chicago, IL: University of Chicago Press.

Blau, P. M. (1964). Exchange and power in social life. New York, NY: Wiley.

Borgatti, S. P., \& Cross, R. (2003). A relational view of information seeking and learning in social networks. Management Science, 49, 432-45.

Bourricaud, F. (1964). Sur deux mécanismes de personnalisation du pouvoir. In L. Hamon \& A. Mabileau (Eds.), La personnalisation du pouvoir. Paris: Presses Universitaires de France.

Brass, D. J. (1984). Being in the right place: A structural analysis of individual influence in an organization. Administrative Science Quarterly, 29, 518-539.

Breiger, R. L. (2010). Dualities of culture and structure: Seeing through cultural holes. In J. Fuhse \& S. Mützel (Eds.), Relationale Soziologie: Zur kulturellen Wende der Netzwerkforschung (pp. 37-47). Berlin: Springer Verlag.

Burt, R. S. (2004). Structural holes and good ideas. American Journal of Sociology, 110, 349-399.

Cross, R., Borgatti, S. P., \& Parker, A. (2001). Beyond answers: Dimensions of the advice network. Social Networks, 23, 215-235.

Esser, H. (1996). Die definition der situation. Kölner Zeitschrift für Soziologie und Sozialpsychologie, 48, 1-34.

Fine, G. A., \& Kleinman, Sh. (1983). Network and meaning: An interactionist approach to structure. Symbolic Interaction, 6, 97-110.

Goffman, E. (1974). Frame analysis: An essay on the organization of experience. New York, NY: Harper \& Row.

Gonos, G. (1977). Situation versus frame: The interactionist and the structuralist analysis of everyday life. American Sociological Review, 42, 854-867.

Hughes, E. C. (1945). Dilemmas and contradictions of status. American Journal of Sociology, $50,353-359$.

Ibarra, H., \& Andrews, S. B. (1993). Power, social influence and sense making: Effects of network centrality and proximity on employee perceptions. Administrative Science Quarterly, $38,277-303$. 
Kilduff, M., \& Tsai, W. (2003). Social networks and organizations. Thousand Oaks, CA: Sage.

Krackhardt, D. (1990). Assessing the political landscape: Structure, cognition, and power in organizations. Administrative Science Quarterly, 35, 342-369.

Lazega, E. (1990). Internal politics and the interactive elaboration of information in workgroups. Human Relations, 43, 87-101.

Lazega, E. (1992). Micropolitics of knowledge: Communication and indirect control in workgroups. New York, NY: Aldine-de Gruyter.

Lazega, E. (2003). Rationalité, discipline sociale et structure. Revue Française de Sociologie, $44,305-330$.

Lazega, E. (2011a). Pertinence et structure. Revue Suisse de Sociologie, 37, 127-149.

Lazega, E. (2011b). Four and half centuries of new (new) law and economics: Legal pragmatism, discreet joint regulation and institutional capture at the Commercial Court of Paris. In U. de Vries \& L. Francot-Timmermans (Eds.), Law's environment: Critical legal perspectives. The Hague: Eleven International Publishing.

Lazega, E., \& Favereau, O. (2002). Introduction. In O. Favereau \& E. Lazega (Eds.), Conventions and structures in economic organization: Markets, networks, and hierarchies (pp. 1-28). Cheltenham: Edward Elgar Publishing.

Lazega, E., Lemercier, C., \& Mounier, L. (2006). A spinning top model of formal structure and informal behaviour: Dynamics of advice networks in a commercial court. European Management Review, 3, 113-122.

Lazega, E., \& Mounier, L. (2003). Interlocking judges: On joint external and self-governance of markets. In Research in the sociology of organizations (Vol. 20, pp. 267-296). Bingley, UK: Emerald Group Publishing Ltd.

Lazega, E., \& Mounier, L. (2009). Polynormativité et contrôle social du monde des affaires: Le cas de l'interventionnisme et de la punitivité des juges du Tribunal de Commerce de Paris. Droit et Société, 71, 103-132.

Lazega, E., \& Mounier, L. (2012). Networks of institutional capture. In B. Vedres \& M. Scotti (Eds.), Networks in social policy problems (pp. 124-137). Cambridge, UK: Cambridge University Press.

Lazega, E., Mounier, L., Snijders, T. A. B., \& Tubaro, P. (2012). Norms, status and the dynamics of advice networks. Social Networks, 34, 323-332.

Lazega, E., \& Pattison, P. (1999). Multiplexity, generalized exchange and cooperation in organizations. Social Networks, 21, 67-90.

Lazega, E., Sapulete, E., \& Mounier, L. (2011). Structural stability regardless of membership turnover? The added value of blockmodelling in the analysis of network evolution. Quality \& Quantity, 45, 129-144.

Lazega, E., \& Van Duijn, M. (1997). Position in formal structure, personal characteristics and choices of advisors in a law firm: A logistic regression model for dyadic network data. Social Networks, 19, 375-397.

Lindenberg, S. (1997). Grounding groups in theory: Functional, cognitive and structural interdependencies. Advances in Group Processes, 14, 281-331.

Lindenberg, S. (2006). Social rationality. In J. Beckert \& M. Zafirovski (Eds.), International encyclopedia of economic sociology (pp. 616-618). New York, NY: Routledge.

Maines, D. R. (1977). Social organization and social structure in symbolic interactionist thought. Annual Review of Sociology, 3, 235-259.

McCall, G. J., \& Simmons, J. L. (1966). Identities and interactions. New York, NY: Collier-Macmillan. 
McDonald, M. L., \& Westphal, J. D. (2003). Getting by with the advice of their friends: CEOs' advice networks and firms' strategic responses to poor performance. Administrative Science Quarterly, 48, 1-32.

McHugh, P. (1968). Defining the situation. Indianapolis, IN: Bobbs-Merrill.

McPherson, J. M., Smith-Lovin, L., \& Cook, J. M. (2001). Birds of a feather: Homophily in social networks. Annual Review of Sociology, 27, 415-444.

Mizruchi, M. S., \& Stearns, L. B. (2001). Getting deals done: The use of social networks in bank decision making. American Sociological Review, 66, 647-741.

Mohr, J. W., \& White, H. C. (2008). How to model an institution. Theory and Society, 37, 485-512.

Pachucki, M. A., \& Breiger, R. L. (2010). Cultural holes: Beyond relationality in social networks and culture. Annual Review of Sociology, 36, 205-224.

Reynaud, J.-D. (1989). Les Règles du jeu: L'Action collective et la régulation sociale. Paris: Armand Colin.

Rulke, D. L., \& Galaskiewicz, J. (2000). Distribution of knowledge, group network structure, and group performance. Management Science, 46, 612-625.

Schultz, J., \& Breiger, R. L. (2010). The strength of weak culture. Poetics: Journal of Empirical Research on Culture, the Media, and the Arts, 38, 610-24.

Selznick, Ph. (1957). Leadership in administration. Evanston, IL: Row, Peterson \& Co.

Smithson, M. (1985). Toward a social theory of ignorance. Journal for the Theory of Social Behavior, 15, 151-172.

Stryker, Sh. (1980). Symbolic interactionism: A social structural version. London: Benjamin/ Cummings.

Tsai, W. (2002). Social structure of coopetition within a multiunit organization: Coordination, competition, and intra-organizational knowledge sharing. Organization Science, 13, 179-190.

White, H. C. (2008). Identity and control: How social formations emerge. Princeton, NJ: Princeton University Press. 